\title{
КЛАССИФИКАЦИЯ И ВИДЫ ПОТРЕБИТЕЛЬСКОГО ПОВЕДЕНИЯ ЭКОНОМИЧЕСКИХ СУБЪЕКТОВ
}

\section{(c) 2021 Махмудова Гулрух Равшанбековна}

аспирант

Казанский (Приволжский) федеральный университет, Россия, Республика Татарстан, Казань

E-mail: happy-daisy@rambler.ru

В работе уточнено содержание модели потребительского поведения, которая представляет собой комплекс взаимосвязанных устойчивых стереотипов и механизмов потребительского выбора субъекта социально-экономических отношений, формирующийся и реализующийся на основании макроэкономических, мезоэкономических, институциональных и социально-психологических факторов, финансовых возможностей и ограничений экономического субъекта и ожиданий их изменения в перспективе, ориентированный на обеспечение устойчивого повышения индивидуальной социально-экономической эффективности такого рода субъекта (личностного благосостояния индивида или домохозяйства, финансовой результативности и рыночной стоимости организации, как субъекта коммерческого потребления, степени и качества реализации функций государства в области государственного и муниципального заказа).

Расширена классификация видов потребительского поведения по таким признакам дифференциации, как степень обоснованности, интегративность, легальность, социальная эффективность потребительского поведения и возможности использования опыта иных экономических субъектов в процессе его развития. В целом, расширенная классификация видов потребительского поведения позволит экономическим субъектам выбрать наиболее предпочтительный его вариант, исходя из собственной стратегии развития и состояния внешних финансово-экономических факторов, а органам государственного регулирования - сформировать политику интенсивного развития наиболее предпочтительных в социально-экономическом плане видов потребительского поведения в национальной экономике.

Ключевые слова: потребительское поведение, предельная полезность, маржинализм, маркетинг, ассиметричность информации.

Содержание потребительского поведения, как и любой иной категории экономической теории, проявляется в рамках многообразия его видов. Необходимо отметить, что часть видов потребительского поведения, в частности дифференцированных по критериям рациональности или информационной ассиметрии, типам отраслевых рынков и т.п. достаточно подробно рассматривается в имеющейся литературе по исследуемой нами проблеме. Вместе с тем, представляется целесообразным для более комплексного рассмотрения анализируемого нами социально-экономического понятия расширение спектра классификационных признаков дифференциации видов потребительского поведения (таблица 1).

Актуальной представляется и дифференциация видов потребительского поведения в зависимости от характера ориентации акторов потребительского выбора на успешные практи- ки в рассматриваемой области. В сфере индивидуального потребительского поведения такого рода ориентация обычно обуславливается тенденциями моды и, соответственно, зачастую вызывает избыточное, в принципе, социально деструктивное потребление товаров и услуг, фактическая необходимость которых для индивидов, принимающих решение о покупке, сомнительна или вовсе отсутствует (постоянно меняющиеся новые модели гаджетов, новые линии модной одежды, обуви, как правило достаточно дорогостоящие и т.п.).

В сфере же корпоративного потребительского поведения ориентация на передовые практики в области организации и осуществления закупок обычно носит потенциально эффективный в финансово-экономическом аспекте характер. Данный процесс обычно осуществляется в форме корпоративного бенчмаркинга в сфере управления закупками сырья, комплектующих, 
Таблиц̧а 1. Классификация видов потребительского поведения экономических субъектов (уточнено и дополнено автором диссертационного исследования)

\begin{tabular}{|c|c|}
\hline $\begin{array}{c}\text { Классификационные } \\
\text { признаки }\end{array}$ & Виды потребительского поведения \\
\hline \multicolumn{2}{|c|}{ Существующие классификационные признаки } \\
\hline $\begin{array}{l}\text { 1. Субъект потребительского } \\
\text { поведения }\end{array}$ & $\begin{array}{l}\text { - потребительское поведение индивидов и домохозяйств; } \\
\text { - потребительское поведение организаций различных отраслей экономики; } \\
\text { - потребительское поведение государства в рамках систем государственно- } \\
\text { го и муниципального заказа. }\end{array}$ \\
\hline $\begin{array}{l}\text { 2. Объект потребительского } \\
\text { поведения }\end{array}$ & $\begin{array}{l}\text { - потребительское поведение на рынке товаров; } \\
\text { - потребительское поведение на рынке работ; } \\
\text { - потребительское поведение на рынке услуг. }\end{array}$ \\
\hline $\begin{array}{l}\text { 3. Степень рациональности } \\
\text { потребительского поведения }\end{array}$ & $\begin{array}{l}\text { - рациональное потребительское поведение; } \\
\text { - ограниченно рациональное потребительское поведение; } \\
\text { - иррациональное потребительское поведение. }\end{array}$ \\
\hline $\begin{array}{l}\text { 4. Интенсивность потреби- } \\
\text { тельского поведения }\end{array}$ & $\begin{array}{l}\text { - регулярное потребительское поведение; } \\
\text { - разовое (иррегулярное) потребительское поведение. }\end{array}$ \\
\hline $\begin{array}{l}\text { 5. Активность использования } \\
\text { маркетингового фактора в } \\
\text { потребительском поведении }\end{array}$ & $\begin{array}{l}\text { - потребительское поведение, полностью сформированное под влиянием } \\
\text { технологий маркетинга; } \\
\text { - потребительское поведение, на характер которого технологии маркетинга } \\
\text { оказали фрагментарное влияние; } \\
\text { - потребительское поведение, сформированное не на основании использо- } \\
\text { вания технологий и инструментов маркетинговой деятельности. }\end{array}$ \\
\hline \multicolumn{2}{|c|}{ Дополненные автором классификационные признаки } \\
\hline $\begin{array}{l}\text { 6. Степень обоснованности } \\
\text { потребительского поведения }\end{array}$ & $\begin{array}{l}\text { - потребительское поведение, сформированное на основании исключи- } \\
\text { тельно интуиции и опыта экономического субъекта; } \\
\text { - потребительское поведение, сформированное в результате использования } \\
\text { экспертных оценок и экспертных систем поддержки принятия потребитель- } \\
\text { ских решений различного уровня, например консалтинга; } \\
\text { - потребительское поведение, направления и приоритеты которого фор- } \\
\text { мируются на основании применения экономико-математических методов и } \\
\text { моделей. }\end{array}$ \\
\hline $\begin{array}{l}\text { 7. Ориентация на эффектив- } \\
\text { ные практики потребитель- } \\
\text { ского поведения }\end{array}$ & $\begin{array}{l}\text { - потребительское поведение, системно ориентирующееся на некоторый } \\
\text { позитивный внешний опыт (мода поведения индивидуальных потребите- } \\
\text { лей, бенчмаркинг закупок - для поведения юридических лиц); } \\
\text { - потребительское поведение, в рамках которого фрагментарно использу- } \\
\text { ется опыт иных экономических субъектов; } \\
\text { - потребительское поведение, в рамках которого отсутствует ориентация } \\
\text { на опыт других экономических субъектов в данной области. }\end{array}$ \\
\hline $\begin{array}{l}\text { 8. Легальность потребитель- } \\
\text { ского поведения }\end{array}$ & $\begin{array}{l}\text { - абсолютно легальное потребительское поведение; } \\
\text { - нелегальное в гражданско-правовом аспекте потребительское поведение; } \\
\text { - нелегальное в уголовно-правовом аспекте потребительское поведение. }\end{array}$ \\
\hline $\begin{array}{l}\text { 9. Степень интеграции по- } \\
\text { требительского поведения с } \\
\text { другими видами экономиче- } \\
\text { ского поведения субъекта }\end{array}$ & $\begin{array}{l}\text { - потребительское поведение, интегрированное с другими видами эконо- } \\
\text { мического поведения субъекта; } \\
\text { - потребительское поведение, дезинтегрированное с иными видами } \\
\text { экономического поведения субъекта (поведением в области формирования } \\
\text { доходов, сбережений и т.п.). }\end{array}$ \\
\hline $\begin{array}{l}\text { 10. Социальная эффектив- } \\
\text { ность потребительского } \\
\text { поведения }\end{array}$ & $\begin{array}{l}\text { - социально эффективное потребительское поведение; } \\
\text { - социально деструктивное потребительское поведение. }\end{array}$ \\
\hline
\end{tabular}

основных фондов, когда компания копирует передовые практики отраслевых лидеров в рассматриваемой области. Укрупненная динамика интенсивности использования потенциала бенчмаркинга закупок в рамках потребительского поведения компаний РФ приведена на рис. 1.

Как показано на рис. 1, за 2013-2020 гг. доля компаний РФ, относительно регулярно исполь- зующих потенциал отраслевого бенчмаркинга для рационализации собственной модели потребительского поведения, увеличилась на 6,0 процентных пункта до 15,3\% от общего количества компаний национальной экономики. Вместе с тем, в государствах ЕС и США, согласно, в частности, укрупненной оценке И.Адизеса, ресурсы бенчмаркинга для совершенствования 


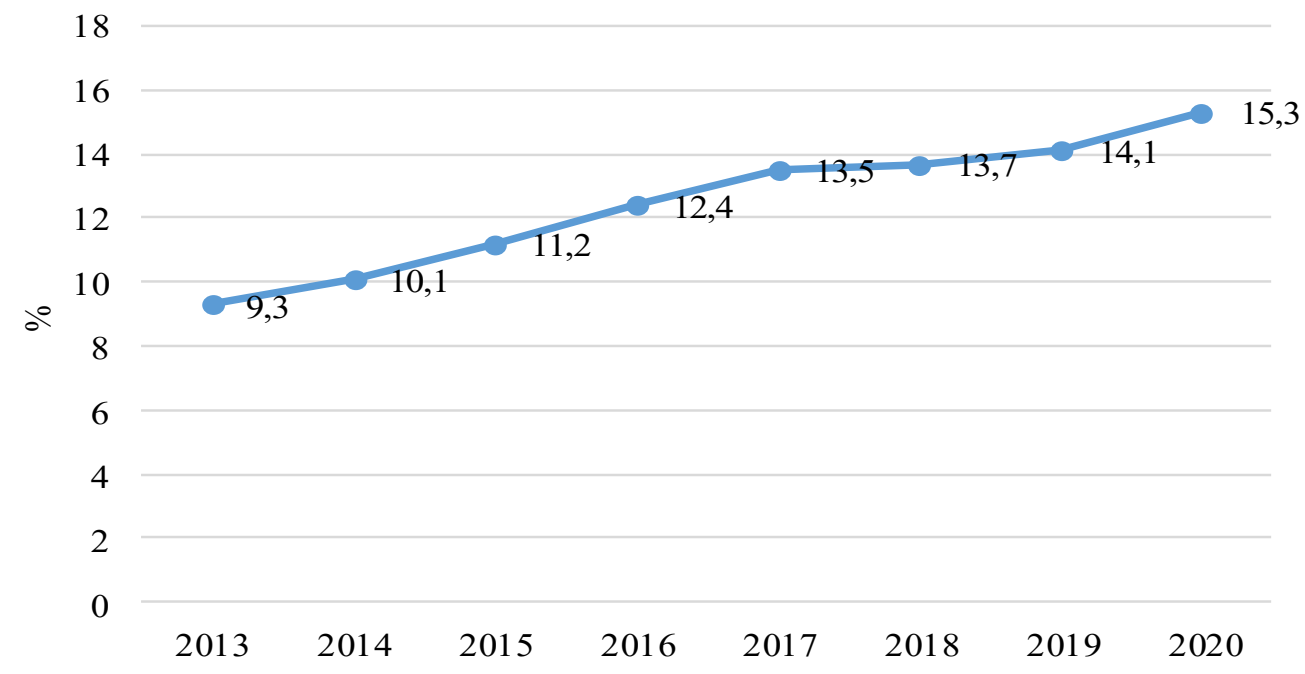

Puc. 1. Динамика доли компаний РФ, регулярно использующих потенциал бенчмаркинга для рационализации потребительского поведения (реорганизации системы закупок), \% от общего количества субъектов хозяйствования [5].

системы корпоративных закупок используют порядка 60-70\% организаций [2, С.317], в т.ч. относящихся к сфере малого и среднего предпринимательства, что, при прочих равных условиях, положительно сказывается на параметрах финансово-экономической эффективности их развития.

Существенное значение имеет и классификация видов потребительского поведения в зависимости от уровня легальности последнего. При этом основными вариантами нелегального потребительского поведения являются:

- приобретение индивидуальными потребителями товаров, работ, услуг на легальных рынках без выдачи кассового чека, то есть в рамках незаконного наличного оборота денежных средств;
- закупка товарно-материальных ценностей компаниями различного профиля без должного гражданско-правового оформления такого рода операций и обычно опять-таки с использованием механизмов т.н. «черного нала»;

- приобретение физическими лицами товаров и услуг на любых видах нелегальных, в т.ч. криминальных, рынков (наркотические препараты, услуги игорного бизнеса за пределами разрешенных игорных зон, услуги индустрии интим-услуг и т.п.);

- любые формы коррупционных трансакций граждан и организаций (формы реализации коррупционной модели потребительского поведения, которая практически всегда осуществляется на основании нелегального денежного оборота).

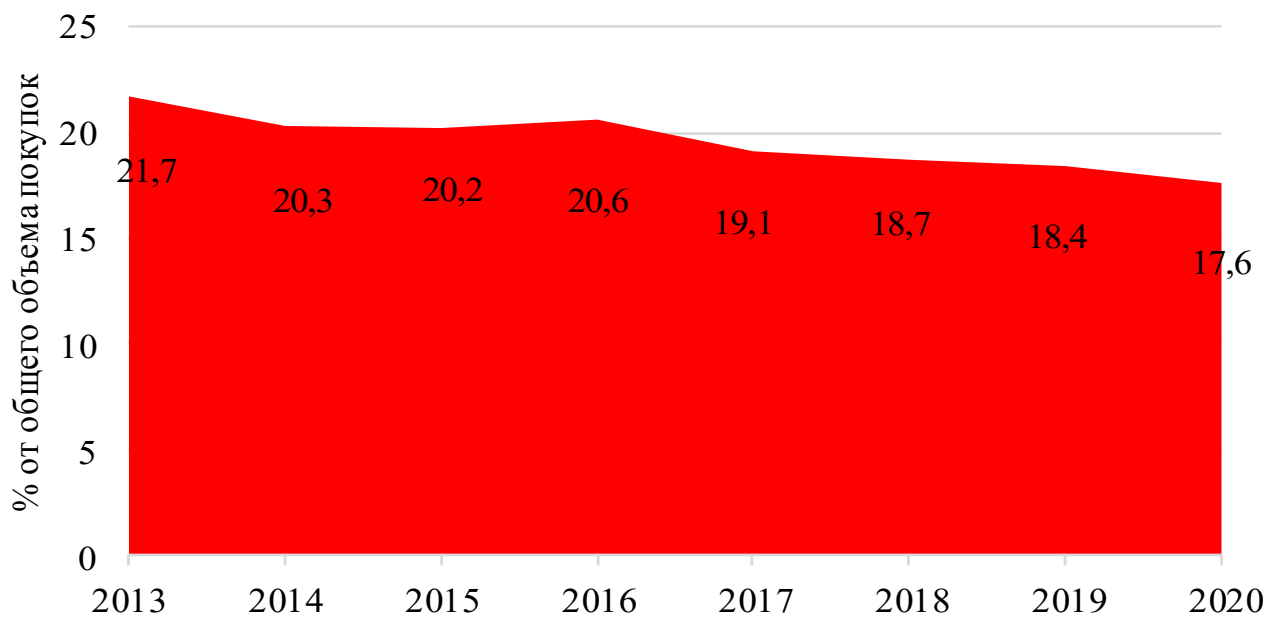

Puc. 2. Динамика доли нелегальных покупок товаров, работ, услуг в экономике РФ, \% от суммарной стоимости покупок всех групп экономических субъектов [8]. 
Как показано на рис. 2 исследования, в 20132020 гг. доля нелегальных покупок в общем объеме потребительского оборота национальной экономики РФ сократилась на 4,1 процентных пункта. Основными причинами данной позитивной тенденции, по нашему мнению, являются активизация процессов противодействия органов государственного финансового контроля и прокурорского надзора России за процессами обналичивания денежных средств в корпоративном секторе экономики; некоторое уменьшение во второй половине 2010 гг. емкости криминальных рынков оборота наркотических средств, в первую очередь в части международного наркотраффика, а также индустрии нелегальных азартных игр.

В зависимости от степени интеграции с другими видами экономического поведения, как показано в таблице 1, предлагается дифференцировать потребительское поведение, тесным образом интегрированное с другими вариантами реализации экономического поведения и, соответственно, дезинтегрированное. При этом основными видами экономического поведения индивидов, с которыми, в идеале, должно быть тесным образом интегрировано, сбалансировано потребительское поведение, являются:

- индивидуальное трудовое поведение;

- поведение в области формирования и развития сбережений домохозяйства (так, еще представители неоклассической экономической теории, в частности А.Маршалл, указывали на неразрывную взаимосвязь процессов потребления и сбережений; так, например, предельная склонность индивида к потреблению является величиной, противоположной предельной склонности к сбережению - сумма данных величин для любого экономического субъекта равна единице [7]);

- поведение в области формирования, развития и, возможно, прекращения семейных отношений, от характера которых также в значительной степени зависят количественные и качественные параметры индивидуального потребительского поведения.

На уровне компаний потребительское поведение должно быть тесным образом интегрировано со следующими видами корпоративного экономического поведения:

- финансово-инвестиционное поведение субъектов хозяйственной деятельности;

- поведение компании в области использо- вания различных видов производственных ресурсов;

- поведение компании в сфере слияний, поглощений и иных типов корпоративной интеграции - так, в принципе, сделка враждебного поглощения может быть в парадигме экономико-теоретического анализа рассмотрена как единичный акт крупной покупки предпринимательского актива, интегрированный с механизмом продажи прежним собственником такого рода актива к осуществлению сделки на выгодных для покупателя условиях.

Наконец, с точки зрения признака социальной эффективности предлагается подразделять потребительское поведение экономического субъекта на социально эффективное и социально деструктивное. При этом любые формы нелегального потребительского поведения, несомненно, являются одновременно социально деструктивными.

Вместе с тем, на наш взгляд, социально деструктивными являются и отдельные варианты легального потребительского поведения граждан и организаций. Так, например, если руководитель предприятия приобретает выраженные предметы роскоши, при этом не индексируя уровень заработной платы собственным наемным работникам, то такого рода экономическое поведение формально является вполне законным (если условиями трудовых договоров не предусмотрен порядок регулярной индексации ставок оплаты труда) - вместе с тем, оно обычно воспринимается обществом как аморальное и, соответственно, вытекающее из такого рода ситуации избыточное потребление материальных благ можно расценивать как социально деструктивное.

При этом ограниченно рациональное поведение может быть характерно не только для конечных индивидуальных потребителей товаров, работ, услуг, но и для компаний различного масштаба и профиля на разных стадиях финансовоэкономической деятельности последней, а также для государства, как особого, но также зачастую не вполне рационального субъекта экономических отношений.

Вопросы формирования и реализации иррационального экономического в целом и, в частности, потребительского поведения рассматриваются в рамках различных школ и направлений экономической и социологической науки, а именно: 
a) в парадигме теории девиантного поведения в рамках различных направлений социологической мысли и общественной философии в целом, в частности в работах 3. Фрейда, Э. Фромма, М. Хайдеггера и других исследователей;

б) в рамках ряда направлений экономической теории неоинституционализма, в частности в исследованиях потребительского поведения Р. Коуза, Дж.Нэша, Ж. Тироля и других ученых;

в) в системе координат такого актуального направления как теоретического, так и прикладного экономического анализа современных социально-экономических процессов, как экономика коррупции, возможности которой могут быть использованы для исследования отдельных особенностей иррационального поведения, в частности, корпораций при реализации коррупционных схем потребления сырья, материалов, оборудования, а также отдельных представителей органов государственного и муниципального управления, например при осуществлении деятельности в рамках организации государственного заказа.

В целом, в рамках современной экономической теории под иррациональным экономическим поведением понимаются алогичные формы поведения различных групп экономических субъектов, которые, как правило, являются деструктивными как для самих акторов поведен- ческих действий, так и для окружающего их микро- или макросоциума.

В наиболее общем виде рациональное, ограниченно рациональное и иррациональное поведение физических лиц можно представить в рамках принятия решения о покупке по соотношению двух основных, хотя и относительно условных параметров (поскольку de facto диапазон параметров при принятии решения о покупке обычно значительно шире, однако такого рода дополнительные потребительские параметры часто и являются детерминантами ограничения рациональности потребительского поведения) - сочетания цены и качества товара (работы, услуги) (рис. 3).

Таким образом, в рамках рационального потребительского поведения, естественно, выбирается товар с высоким уровнем качества по минимальной цене. При наиболее распространенным в практике экономической деятельности варианте ограниченно рационального потребительского поведения выбирается некоторый не оптимальный, но достаточно удовлетворительный вариант. По мнению, в частности, Г. Саймона основными причинами ограниченно рационального потребительского поведения являются [9, С.54]:

- наличие информационной асимметрии - сложности доступа и обработки информации о всех возможных вариантах покупки од-

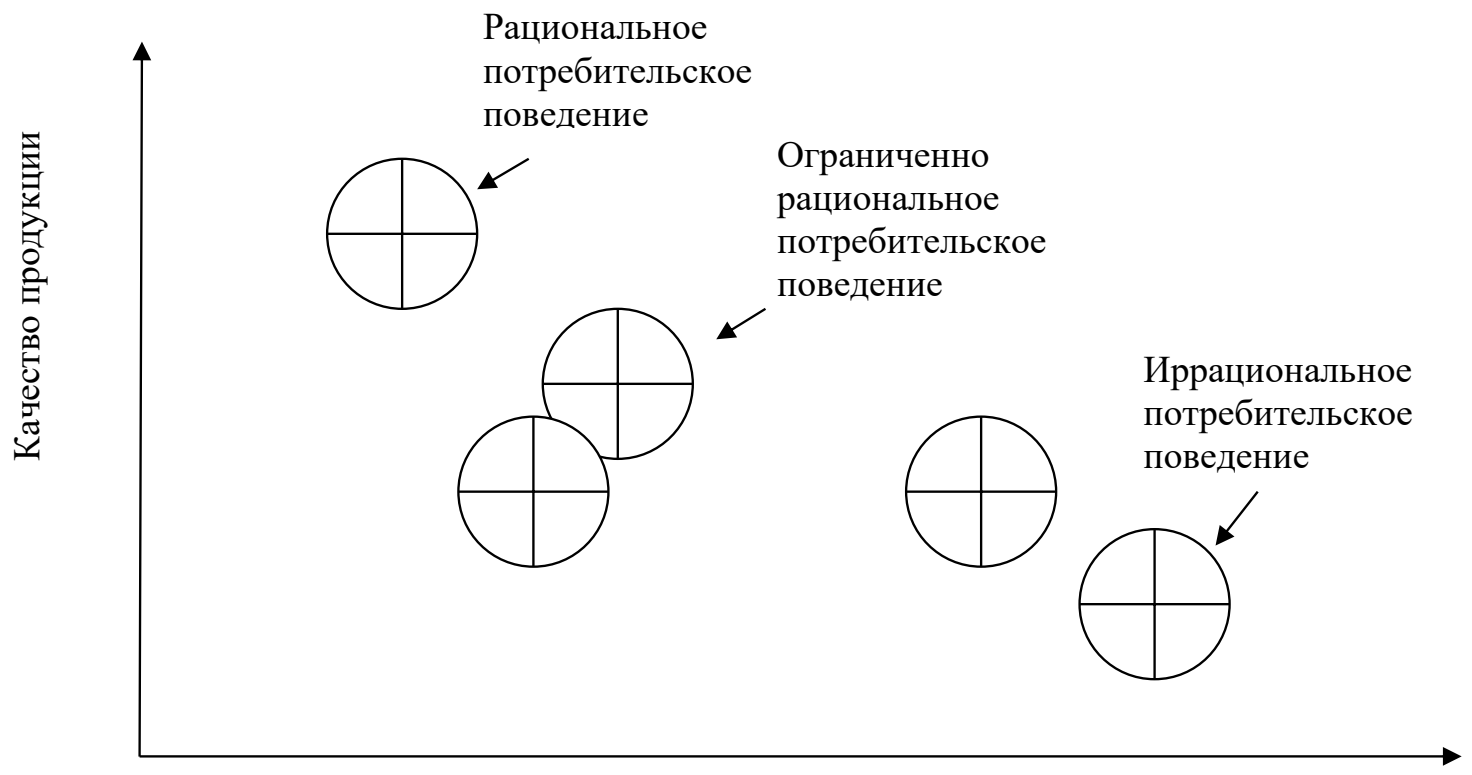

Цена

Рис. 3. Наиболее общий вид рационального, ограниченно рационального и иррационального потребительского поведения [10]. 
ного и того же товара (так, сделать оптимальный выбор даже при условии принятия решения о покупке в рамках виртуального информационного пространства - достаточно сложно осуществить сравнительный мониторинг всех профильных интернет-магазинов и даже универсальных сетевых маркетплейсов, а существующие в сети автоматизированные системы, ориентированные на повышение эффективности такого рода потребительского выбора, например, сопоставляющие цены в различных точках интернетпродаж, далеко не всегда носят объективный и комплексный характер);

- не вполне эффективные когнитивные способности лица, принимающего решение о покупке;

- специальное маркетинговое манипулирование (классический пример - расположение в супермаркете на полках на уровне глаз среднестатистического покупателя самых дорогих ассортиментных позиций товаров);

- дефицит времени потребителя, необходимого для принятия максимально рационального решения о покупке конкретного товара, работы, услуги.

Можно выделить крайне редкие, но все же существующие формы иррационального, но одновременно социально позитивного экономического поведения индивидов, например: крайне интенсивная индивидуальная благотворительная деятельность, зачастую осуществляемая в ущерб личным финансовым планам, целям максимизации личного благосостояния (одним из наиболее характерных примеров такого рода активной благотворительности являлся предприниматель из г. Казань А.Г.Галимзянов, который в 1980-2010 гг. перечислял практически все свои значительные доходы детским домам, сам живя практически в нищете); общественно-политическая активность индивидов, осуществляемая зачастую в ущерб личным целям профессионального развития, приоритетам обеспечения индивидуальной безопасности и т.п.; отдельные направления волонтерской деятельности граждан, в том случае, если они осуществляются в ущерб основной трудовой деятельности.

\section{Библиографический список}

1. Автономов В. Образ человека в политической экономии // М3 и МО. - 1990. - № 1. - С. 21.

2. Адизес И. Управление жизненным циклом корпорации. М.: Альпина Паблишер, 2021. 512c.

3. Вебер М. Избранные произведения. - М.: Прогресс, 1990. - 36 с.

4. Грачева Т. А. Поведение экономического субъекта в условиях становления рыночных институтов / Дис. ... канд. экон. наук: 08.00.01. - М.: 2005. - 165 с.

5. Дорохов А.В. Проблемы развития потребительского поведения в России в условиях пандемии // Бизнес и финансы. 2021. № 4. - С.34

6. Леонтьев В. В. Экономические эссе. Теории, исследования, факты и политика. - М: Политиздат, 1990. - 53 c.

7. Маршалл А. Принципы политической экономии / А. Маршалл. - М.: Прогресс, 1993. - Т.1. С.171.

8. Российская экономика: проблемы и перспективы. - М.: Изд-во Института экономической политики, 2021. C. 349.

9. Саймон Г.А. Теория принятия решений в экономической теории и в науке о поведении // Вехи экономической мысли Т.2. Теория фирмы / Под ред. В. М. Гальперина - СПб.: Экономическая школа, 2000.

10. Самсонов А.Д. К вопросу об особенностях потребительского поведения // Вестник экономики и менеджмента. 2020. № 4. С.71

11. Фахрутдинова Е. В. Диалектика потребностей человека// Экономические науки. 2009. № 57. С.43-47.

12. Фахрутдинова Е.В., Васильев А.К. Потребности и качество жизни человека: аспекты взаимодействия. Экономические науки. 2009. № 59. С.90-93.

13. Ядгаров Р.С. Истории экономических учении // Учеб. 3-е изд. - М.: ИНФРА-М, 2000. - 176 с.

14. Blanc S., Massaglia S., Borra D., Mosso A., Merlino V.M. Animal welfare and gender: a nexus in awareness and preference when choosing fresh beef meat? // Journal of Animal Science. - 2020. - Volume 19, Issue 1. - Pp. $410-420$

15. Rondoni A., Asioli D., Millan E. Consumer behaviour, perceptions, and preferences towards eggs: A review of the literature and discussion of industry implications // Trends in Food Science and Technology. - 2020. - Volume 106. - Pp. 391-401. 
16. Testa F., Iovino R., Iraldo F. The circular economy and consumer behaviour: The mediating // Business Strategy and the Environment. - 2020. - Volume 29, Issue 8. - Pp. 391-401.

17. Nimri R., Patiar A., Jin X. The determinants of consumers' intention of purchasing green hotel accommodation: Extending the theory of planned behavior // Journal of Hospitality and Tourism Management. - 2020. - Volume 45. - Pp. 535-543.

18. Khanra S., Dhir A., Kaur P., Joseph R. P. Factors influencing the adoption postponement of mobile payment services in the hospitality sector during a pandemic // Journal of Hospitality and Tourism Management. - 2020. - Volume 46. - Pp. 26-39.

19. Fakhrutdinova E., Severyanov O., Shigabutdinov A., Fakhrutdinov R. The crisis of 1988 in Russia: political intervention and its implication// Life Science Journal. 2014. T. 11. № 6s. C. 442-447. 